\title{
Knowledge of, and attitudes towards, Voluntary HIV Counselling and Testing services amongst adolescent high school students in Addis Ababa, Ethiopia
}

\author{
Authors: \\ Abraham A. Gatta ${ }^{1}$ \\ Gloria Thupayagale- \\ Tshweneagae $^{2}$

\section{Affiliations:} \\ ${ }^{1}$ Ethiopian Federal Ministry \\ of Health, Addis Ababa, \\ Ethiopia \\ ${ }^{2}$ Department of Health \\ Studies, University of \\ South Africa, South Africa

\section{Correspondence to:} \\ Gloria Thupayagale- \\ Tshweneagae \\ Email: \\ tshweg@unisa.ac.za \\ Postal address: \\ PO Box 392, Pretoria 0003, \\ South Africa

\section{Dates:} \\ Received: 24 Feb. 2012 \\ Accepted: 13 Oct. 2012 \\ Published: 06 Dec. 2012 \\ How to cite this article: \\ Gatta, A.A. \&, Thupayagale- \\ Tshweneagae, G., 2012, \\ 'Knowledge of, and attitudes \\ towards, Voluntary HIV \\ Counselling and Testing \\ services amongst adolescent \\ high school students in Addis \\ Ababa, Ethiopia', Curationis \\ 35(1), Art. \#103, 8 pages. \\ http://dx.doi.org/10.4102/ \\ curationis.v35i1.103
}

C 2012. The Authors. Licensee: AOSIS OpenJournals. This work is licensed under the Creative Commons Attribution License.
Voluntary HIV counselling and testing (VHCT) is one of the key strategies in the prevention of HIV in Ethiopia. However, utilisation of the VHCT services amongst adolescents has been reported as low by previous studies. The purpose of this study was to investigate adolescents' knowledge and attitudes towards VHCT services amongst adolescents attending high school in Addis Ababa, the capital city of Ethiopia. A cross-sectional school-based design using quantitative methods was employed to attain the objectives of the study. Data collection was done using self-administered structured questionnaires amongst 378 adolescent high school students. Data were analysed using the Statistical Package for Social Sciences (SPSS). The findings revealed that $75.7 \%$ of students are aware of the voluntary HIV counselling and testing services; $62.2 \%$ use the services and suggested that VHCT services should be located in schools and youth clubs for better access by adolescents. Thirty-two percent of respondents rated themselves at risk of HIV infection and 35.2\% were not willing to disclose their HIVpositive status to anybody. The findings of the study clearly indicate a need for a more accessible voluntary HIV counselling and testing services for adolescents.

\section{Introduction}

HIV counselling and testing has been identified as the key entry point to prevention, care, treatment and support services. It is where people learn whether they are infected, and are helped to understand the implications of their HIV status and make informed choices for the future. HIV counselling and testing (HCT) is now acknowledged as an efficacious and pivotal strategy for both HIV and AIDS prevention and care (Pikard 2009:9))

According to UNAIDS (2010:16) nearly 12 million young people in the world (15-24 years of age) are living with HIV and AIDS; and more than 7000 young people become infected with HIV every day. Young people have limited access to information and services. In particular, young girls and young women are more biologically vulnerable to HIV infection than are mature women and men (USAID/Family Health International 2004:36-45). According to Lyons, (2005:3) $60 \%$ of these young people are adolescents between $14-19$ years.

Studies done both in developed (CDC HIV and AIDS surveillance Report, 2004; Hall, Ruiguang, Rhodes et al. 2008:523) and developing countries (Mwandira 2008; Thupayagale -Tshweneagae 2010:34) recognises adolescent friendly services such as voluntary HIV counselling and testing (VHCT) as the best modem of educating adolescents about HIV and AIDS related risks. The majority of adolescents may be at risk of HIV infection due to their engagement in unsafe sex. Young people are also being at risk for HIV infection from unsafe injection drug use, exposure to contaminated blood product or unsterilised skin-piecing procedures. In Africa alone, an estimated 1.7 million young people are infected annually. Preventing HIV amongst adolescents is particularly critical in Sub Saharan Africa (SSA), where in many countries adolescents comprise more than $30 \%$ of the population and general HIV prevalence rates often exceed $10 \%$ (Kabiru, Beguy, Crichton \& Zulu 2011:3).

Adolescents are particularly vulnerable to HIV because of the strong influence of peer pressure and the development of their sexual and social identities, which often lead to experimentation. As they are initiating sexual behaviour, counselling for safe practice is vital. Adolescents should be counselled to delay their sexual debut and practice abstinence (Lyons 2005:3).

\section{Problem statement}

The prevalence of HIV and AIDS amongst adolescents in Ethiopia is 4.8\%. Some studies, (Alemu, Abseno, Degu, Wondmikun \& Amasulu 2004:85; Tegegn, Yazachew \& Gelaw 2008: 244) attribute the high prevalence of HIV and AIDS amongst the youth to poor understanding of the sources of transmission, lack of relevant knowledge; attitudinal problems and unfriendly services for 
adolescents. HIV pandemic is a major threat to adolescents; understanding how to prevent transmission is the first step to avoid infection (United Nations 2010b:41-46). This is especially important for adolescents and the youth who, in 2008, accounted for $40 \%$ of new HIV infections worldwide (United Nations 2010b:41-46). Comprehensive and correct knowledge of HIV amongst this group is still unacceptably low in most countries (United Nations 2010b:41-46).

\section{Background}

Ethiopia is one of countries with the highest incidence of HIV and AIDS in sub-Saharan Africa (UNAIDS 2010:260). The first two people were diagnosed with AIDS in 1986 and since then the country has had many deaths due to AIDS. The point prevalence estimate in 2007 showed that the number of people living with HIV and AIDS was 977394 and of these 578018 $(59 \%)$ were females. The national adult HIV prevalence in the same year was estimated to be $2.1 \%$, of which $7.7 \%$ was from urban and $0.9 \%$ from rural areas (FMOH/HAPCO June 2007). According to the 2006 AIDS report in Ethiopia, people between 15-24 years had the highest prevalence of HIV, 5.6\% (FMOH and National HAPCO 2006).

HIV counselling and testing have been identified as the key entry point to prevention, care, treatment and support services, where people learn whether they are infected, and are helped to understand the implications of their HIV status and make informed choices for the future. Currently, most people remain unaware of their HIV status for various reasons. However, with the development of affordable and effective medical care for people living with HIV, the demand for testing has rapidly increased, creating an urgent need to improve access and quality of service (Joint Publications of IPPF South Asia Regional office and UNFPA 2004).

\section{Voluntary HIV counselling and testing (VHCT) services}

VHCT is a process in which individuals or couples undergo counselling to enable them to make informed choices about being tested for HIV. The decision to be tested must be entirely that of the couple or individual being tested (Shangula 2006:23). HIV counselling and testing have been identified as the key to prevention, care, treatment and support services. Following counselling and testing, people learn whether or not they are infected and are helped to understand the implications of their HIV status and make informed choices for the future. Because of increased demand, the development of affordable and effective medical care for people living with HIV is urgently needed so as to improve access and quality of service (Joint Publications of IPPF South Asia Regional Office and UNFPA 2004:6).

VHCT is recognised as one of the few potentially effective and affordable methods for reducing the transmission of HIV in developing countries (USAID/Family Health International 2004:1). According to the UNAIDS report, there is very little information on VHCT services and young people (UNAIDS 2001:33). As the same UNAIDS report states, in many areas with high prevalence rates, young people, especially women, are at a high risk of HIV infection and yet they often have no access to VHCT services. The report describes the general vulnerabilities of young people to HIV and, in particular, the vulnerability of young women. Nonetheless, this has not been translated into increasing utilisation of VHCT services.

\section{Definitions of key concept}

According to Tuckman (1978:2) an operation definition must define the exact manner in which a variable or a phenomenon is measured. Scientific definitions of concepts used in the study are given as follows:

Adolescence: The transition from childhood to adulthood that is marked by distinct biological, cognitive, and socio-cultural changes (Ajdukovic 1998:120). According to Boswel et al. (2002:35), the Constitution of the Republic of South Africa (Act 108 of 1996) still regards any person from 0 to 18 years as a child. However, for the purpose of this study an adolescent will refer to secondary school students, aged 15-19 years, in Addis Ababa, Ethiopia.

Attitude: Is an enduring organisation of beliefs, feelings, and behavioural tendencies towards socially significant objects, groups, events or symbols (Hogg \& Vaughan 2005:150).

Counselling: Fontaine \& Fletcher 2004:478) defines counselling as a relationship between two people where one person attempts to assist the other to organise himself or herself better to attain a form of happiness by adjusting to a situation. For the purpose of this paper counselling will mean a purposeful dialogue between a person and care provider aimed at enabling a person to cope with stress and make personal decisions about taking an HIV test.

Discrimination: Is an expression of individual attitudes; a social process used to create and maintain social control to produce and reproduce social inequality; an action or treatment based on stigma and directed towards stigmatisation (Parker \& Aggleton 2002:7).

Knowledge: Kartz (1960) defines knowledge as a function of attitude. It is accumulated external and explicit information belonging to the community, being leveraged by tacit, intrinsic insights which originate within individuals who may act alone or cooperatively in order to control or integrate with their environment (Drucker1993:25). For the purpose of this study respondents were considered to be knowledgeable about HIV prevention if they correctly identified the three main ways to prevent HIV transmission: abstinence, faithfulness to one uninfected partner, and consistent condom use.

VHCT: an acronym for voluntary HIV counselling and testing, a process by which an individual undergoes counselling to enable him or her to make informed choices about being tested for HIV.

\section{Research objectives}

The research objectives of the study are to:

- determine adolescents' knowledge of VHCT

- establish adolescents' attitude towards testing for HIV

- determine factors that influence VHCT utilisation 


\section{Significance of the study}

This study will provide information about attitudes of high school students towards the utilisation of VHCT services. This information could assist policy makers in improving the VHCT services for adolescents who make up the majority of people affected by the HIV and AIDS pandemic in the world, and especially in Ethiopia. The results of this study can also serve as a basis for a larger, more detailed study on what needs to be done to bridge the gap between knowledge, attitudes and the utilisation of VHCT services.

\section{Research methods and design Design}

A cross-sectional school-based design using quantitative methods was employed in this study to assess knowledge about HIV attitudes towards VHCT services, as well as factors influencing the use of these services by adolescent high school students in Addis Ababa, Ethiopia.

\section{Study setting and period}

The area under the control of Addis Ababa City Administration was the study setting. It was chosen because Addis Ababa is the largest city in Ethiopia with a population of 2738 248, which is $3.7 \%$ of the total Ethiopian population (Ethiopia Population Census Commission 2008:10). There are 10 subcities under the control of Addis Ababa City Administration. At the time of the study in 2011, the city contained 66 government-owned senior secondary high schools (grade 9-12) and was home to 131255 secondary level students (City Government of Addis Ababa Education Bureau Planning and Programming Service 2011). The number of high school students in Addis Ababa was also the largest in the country and, therefore, was likely to provide a more accurate representation of urban Ethiopia. The study period was from April 2011 to December 2011.

\section{Study population}

A study population is an aggregate of elements sharing some common set of criteria (Burns \& Grove 2001:366). The population is described in terms of the target population, inclusion criteria, and sampling method. The target population in this study was all senior secondary high school students in Addis Ababa, aged from 15-19 years and enrolled in grades 9-12 for the 2011 academic year. The study population was indrawn from 12 government-owned senior secondary high schools in the Addis Ababa City Administration area, and the total number of students present in these schools was 26289 (City Government of Addis Ababa Education Bureau Planning and Programming Service 2011).

\section{Inclusion criteria}

Inclusion criteria are a set of conditions that must be met for a respondent to be included in the sample (Polit \& Beck 2004:290). Determining the criteria is essential for the delineation of the study sample (Polit \& Beck 2004:290). The inclusion criteria for the research respondents were the following: Daytime high school students attending senior secondary high school (grades 9-12); Aged 15-19 years (late adolescents) because this age group's knowledge and attitudes are believed to be under continuous change (Griesel-Roux 2004:51); Attending government-owned senior secondary high schools - such schools are in the majority and hence admit many more students than the few nongovernmental owned schools under the city administration.

\section{Sample size}

Using a 95\% confidence level of certainty $(\alpha=0.05)$ as an assumption, the computed actual sample size for the study used one sample proportion formula as indicated below (Joubert \& Ehrlich 2007:347). Eighty percent was the expected power (1- $\beta$ ) for the study because it could allow good generalisation and since this level is the probability that a test will produce a significant difference at a given significance level if there is in fact a difference (Joubert \& Ehrlich 2007:346):

$$
\begin{aligned}
& n=\frac{(\mathrm{Z} \alpha / 2)^{2} p(1-p)}{d^{2}} \\
& n=\frac{(1.96)^{2}(0.093 * 0.907)}{(0.03)^{2}}=360
\end{aligned}
$$

Adding 5\% non-response rate

Total sample size $=360+18=378$ respondents

Where:

- $n=$ the required minimum sample size

- level of confidence 95\%, which gives the percentile of normal distribution, $\mathrm{Z}_{\alpha / 2}=1.96$

- $d$ (margin of error) $=0.03$

- $p=$ proportion of being tested $=0.093$

- $1-p=$ proportion of not being tested $=0.907$

- Estimated non-response rate in school youth $=5 \%$

Based on the above assumptions, a total of 378 students were required for the study.

\section{Sampling procedures}

A multi-stage sampling technique was used. The researcher randomly selected, by lottery, 12 high schools from 66 government-owned high schools under Addis Ababa City Administration. The researcher incorporated all ten Addis Ababa City Administration sub-cities in the study so as to ensure the representation of each sub-city. The researcher determined the number of schools from each sub-city based on a proportional sampling procedure. The researcher also randomly selected schools from each sub-city using a lottery method. Data were was collected from students of both genders from each school using proportional sampling. According to Van Dalen (1999:23), proportional sampling provides the researcher with a way of achieving greater representativeness in the sample of the population. 


\section{Data collection}

The respondents completed pre-developed, structured, selfadministered questionnaires. The questionnaires were pretested using the same procedure and with a similar target group. The respondents involved in pre-testing did not participate in the actual study. The pre-tested findings showed that the questionnaires were, on the whole, well developed. For the purpose of assessing the reliability of the instrument Cronbach's Alpha Coefficient tests were performed and the results of the Cronbach's alpha values above 80. A few changes were made to part 3 with questions on sexual history being completely deleted from the questionnaire. The researcher visited all the selected schools, and explained the process to the respondents. All information was collected anonymously and, to ensure the anonymity of the responses, there was no personal identification of the respondents.

\section{Data collection procedure}

After selection of the respondents by random sampling, respondents were given a consent form to sign. Once completed, these were placed in a box provided by the researcher and the box was sealed. In order to preserve anonymity, the consent forms were not attached to the questionnaires. Additional boxes were provided for questionnaires for each grade. The principal investigator handed the questionnaires to the respondents after a thorough explanation and after informed consent had been obtained. The respondents then filled in the questionnaires and dropped them into the box provided. When all respondents had filled out the questionnaires, the principal investigator sealed the box and took it to the principal investigator's office.

\section{Data entry and analysis}

The principal investigator manually checked questionnaires to ensure that each one had been answered in full. The questionnaires were then coded and the data entered and processed by using the Statistical Package for Social Sciences (SPSS) for Windows, Version 17. The results are illustrated in the form of frequency tables and depicted graphically in order to provide an overview of the findings.

\section{Research instrument}

The researcher developed a structured questionnaire with mostly close-ended questions. A few open-ended questions were also included. The questionnaire was structured to gather demographic data; knowledge of HIV and AIDS; knowledge of VHCT services; and attitudes. The following steps were taken to ensure the reliability of these research instruments:

- The purpose of the study was explained to the respondents in order to obtain their cooperation and participation in the study.

- The pilot study was carried out and the necessary adjustments were made to the study.
- The researcher was available throughout the data collection process to answer and explain any aspects of the instruments that might have been unclear.

- Questions were made clear. (No medical terms were used in order to enable respondents to understand what the researcher needed.)

\section{Ethical considerations}

The age of consent in Ethiopia is 15 years (FMOH and Federal HAPCO 2007:4). The ethical protection of adolescents was maintained throughout this study. Before the study began, ethical clearance was obtained from the Research and Ethics Committee of the Department of Health Studies at UNISA. Institutional consent was obtained from the Addis Ababa City Administration after communication was established through a formal letter from UNISA. Informed consent was obtained from respondents before they filled in the questionnaires. Specifically, respondents were informed in writing about the objectives of the study and its benefits in the prevention of HIV and AIDS. Codes were used rather than respondent's names so that the respondents would not be identifiable. Two boxes were provided in each grade, one for the signed consent forms and another for the questionnaires. Both boxes were sealed once all the forms and completed questionnaires respectively had been placed in them.

\section{Results}

The findings from the study are presented according to the question sequence in the questionnaire and are presented according to the following sub-headings: socio-demographic data; knowledge about HIV and AIDS; attitudes towards VHCT; and utilisation of VHCT services.

\section{Socio-demographic data}

Three hundred and seventy-eight adolescents between 15 and 19 years of age completed the self-administered questionnaires with assistance of trained research assistants and supervisors. All respondents completed the questionnaires, providing a $100 \%$ response rate.

Amongst respondents, 55\% $(n=208)$ were female and $45 \%$ $(n=170)$ were male. All respondents were literate as the study included students from Grade 9 to Grade 12. A large majority $(96.8 \% ; n=365)$ of students were unmarried (Figure 1 ).

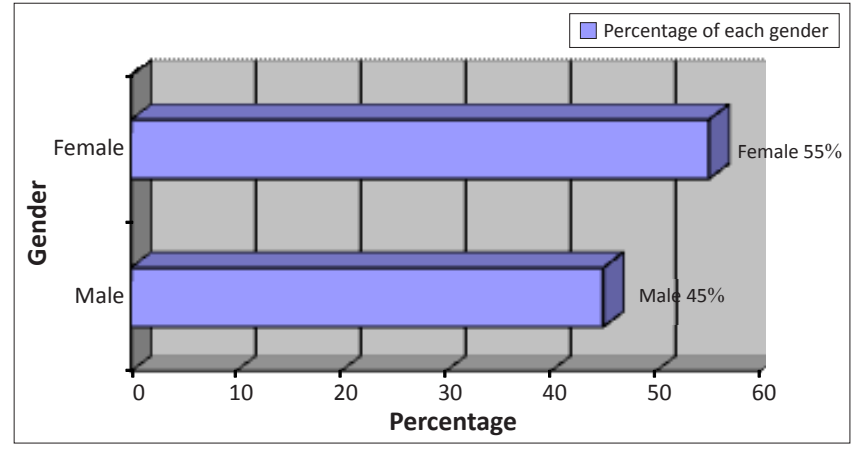

FIGURE 1: Participants by gender. 


\section{Knowledge of voluntary HIV counselling and testing Services}

\section{Modes of HIV transmission}

The modes of HIV transmission mentioned by students were, (1) unprotected sexual intercourse with HIV-positive individuals, (2) infected mother-to-child transmission during delivery (3) breast feeding, (4) sharing sharp materials with HIV-positive individuals, and (5) contaminated blood contact.

Concerning the five modes of HIV transmission mentioned by respondents, $67 \%(n=253)$ correctly identified more than three modes of HIV transmission. Of the respondents, $46.03 \%$ $(n=174)$ mentioned knowledge of three; 10.58\% $(n=40)$ mentioned knowledge of four, whilst $10.85 \%(n=41)$ mentioned knowledge of all seven modes of HIV transmission.

\section{Most relevant prevention methods for young people}

Adolescents identified condom use, abstinence, faithfulness, avoiding sharing sharp materials and blood contact as prevention methods. Amongst those who identified prevention methods, $35.2 \%(n=133)$ and $32.5 \%(n=123)$ identified condom use and abstinence from sexual intercourse, respectively (Table 1).

\section{Attitudes Toward voluntary HIV counselling and testing Services}

Amongst the 378 students who participated in this study, $83.86 \%(n=317)$ had heard about VHCT services whilst $16.14 \%(n=161)$ were not familiar with VHCT services. Over

TABLE 1: Most relevant prevention methods proposed by current respondents. Which prevention method do you think most relevant for $\quad f \quad \%$ young people?

\begin{tabular}{lcc}
\hline Condom use & 133 & 35.2 \\
Abstinence & 123 & 32.5 \\
Faithfulness & 72 & 19.0 \\
Avoid sharp material sharing & 10 & 2.6 \\
Avoid blood contact & 51 & 13.4 \\
\hline
\end{tabular}

$f$, Frequency.

TABLE 2: Individuals who benefit from voluntary HIV counselling and testing services.

\begin{tabular}{lcc}
\hline Who do you think benefits from being tested? & $\boldsymbol{f}$ & $\mathbf{\%}$ \\
\hline HIV positive individuals & 6 & 1.59 \\
HIV negative individuals & 25 & 6.61 \\
Both HIV positive and negative individuals & 347 & 91.80 \\
\hline Total & $\mathbf{3 7 8}$ & $\mathbf{1 0 0}$ \\
\hline
\end{tabular}

$f$, Frequency.

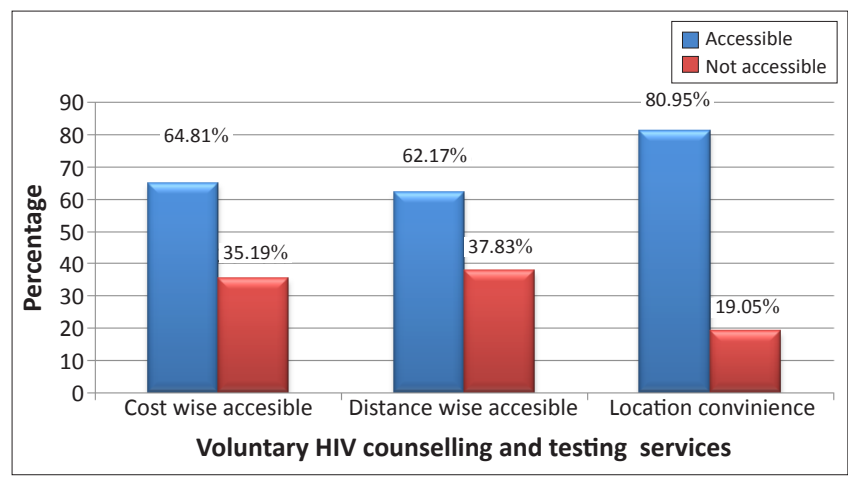

FIGURE 2: Hindrances to utilisation of voluntary HIV counselling and testing services.
$75 \%(n=285)$ of the respondents knew the reasons why a person should be tested. The majority, 64\% $(n=241)$ of those who knew about the VHCT services had been tested and knew their HIV status. However, participants decried the fact that it took more than a week for them to know their results and suggested that it would encourage adolescents to be tested if the results were available immediately. More than $91.8 \%(n=347)$ of respondents mentioned that both HIV-positive and HIV-negative individuals would benefit from being tested (Table 2).

Counselling was also seen as important in testing for HIV. Respondents reported that they would be more comfortable if HIV testing and counselling could be done by other trained adolescents as they would be freer with them. Disclosure of HIV-positive results was met with two differing views. Sixtyseven percent of the participants reported that they would notify their partners and 33\% said that it was not necessary to let one's partner know of one's HIV-positive results.

\section{Utilisation of voluntary HIV counselling and testing Services}

A majority $(n=317)$ knew about VHCT services and actually utilised them. However, respondents decried the fact that VHCT services were very far from their places of residence and were manned by adults who, at times, were not friendly. Paying for services was also identified as a barrier for accessing VHCT services. Respondents suggested that VHCT services should be offered within the schools and be manned by adolescents. Participants views on what hinders utilisation of VHCT services (Figure 2).

\section{Discussions}

The respondents who participated in this study were 15 to 19 years old. This age group was chosen because young people, aged 10 to 24 , account for over $50 \%$ of all HIV infections occurring worldwide. Adolescents are particularly vulnerable to HIV because of the strong influence of peer pressure and the development of their sexual and social identities, which often leads to experimentation. Adolescents should be counselled to delay their sexual debut and to practise abstinence (FMOH and Federal HAPCO 2007:15-16). The findings of the study further showed that adolescents who were not married knew more about HIV transmission and prevention than the few who were married. This notion is also supported in literature because of gender inequalities such as in decision making about sexual intercourse in marriage (UNAIDS 2008:72).

The respondents knew the modes of HIV transmission. Unprotected sex with HIV-infected individuals was the most common mode of HIV transmission cited by the respondents. This finding also emerged in the 2005 Ethiopian Demographic Health Survey amongst youths (Central Statistic Agency 2006:209). Thus, to prevent HIV transmission, it is important that young people practise safe sex through the much advocated ABC methods (abstinence, being faithful to one uninfected partner, and condom use) (Central Statistical Agency 2006:209). Knowledge of HIV transmission modes is 
particularly important for adolescents, since adolescents are greatly threatened by the HIV pandemic and understanding how to prevent HIV transmission is the first step to avoid infection (United Nations 2010b:41)

The finding is also supported by a UNAIDS report which stated that, in sub-Saharan Africa, the high prevalence of HIV infection is due to heterosexual intercourse as the main mode of transmission. This region contains almost two-thirds of all young people living with HIV , $61 \%$ of whom are female (UNAIDS/WHO 2007:8). Therefore, educating adolescents about HIV transmission is important as it provides adolescents with the necessary skills; that is knowledge and understanding of sexual risks, as well as providing a source of peer support and social capital.

The respondents cited both radio and television as their main sources of information for VHCT services and HIV and AIDS in general. Several studies done amongst adolescents also mentioned television and radio as the primary sources of information for adolescents (Abiy 2006:23; Mwandira 2008:29).

Respondents were aware of the importance for all persons of being tested for HIV, whether they tested negative or positive. VHCT offers benefits to those who test either positive or negative (Boswell \& Baggaley 2002:1), yet some respondents believed it was of value only if one was HIV positive. Potential benefits of VHCT are: alleviation of anxiety, increased awareness of vulnerability to HIV, promotion of behaviour change, facilitation of early referral for care, and support and assistance in reducing stigma in the community through education (Boswell \& Baggaley 2002:1). Knowledge of a negative HIV status helps those individuals to make specific decisions around reducing their risk and increasing safer sex practices so they can remain disease free. For those who are HIV infected, there are also benefits because knowledge of their status allows them to take action, to protect their sexual partners, to access treatment, and to plan for their future (Central Statistic Agency 2006:195).

Counselling was also mentioned as being important to HIV testing. The counselling process includes evaluating personal risk of HIV transmission and discussing how to prevent infection (USAID/Family Health International 2004:25). HIV counselling plays two important roles: preventing HIV infection by promoting behavioural change and providing psychosocial support to people infected and affected by HIV (USAID/Family Health International 2004:25). The majority of respondents provided good reasons for the need for counselling, centred around the fact that hearing HIV test results can be emotionally challenging (USAID/Family Health International 2004:25). Having to deliver HIV-positive results is especially demanding in situations where support is inadequate and clients may be vulnerable to discrimination (USAID/Family Health International 2004:25).

The respondents mentioned distance to VHCT services as a barrier to utilisation of services. Respondents suggested that VHCT services should be within school premises for easier access. This finding is supported by the Ethiopian VHCT guideline which says that VHCT services can be provided through the following four models of delivery: (1) integrated services provided in public, NGO, and private health facility settings, as designated VHCT units or under other programmes (FMOH and Federal HAPCO 2007:8); (2) stand-alone counselling and testing services provided at sites outside health facilities (Federal HIV and AIDS Prevention and Control Office 2007:8); (3) outreach VHCT services for special populations such as people in remote rural areas, refugees, and schools (Federal HIV and AIDS Prevention and Control Office 2007:8); and (4) VHCT services provided by trained practitioners in government agencies, NGO, and private sector institutions as part of comprehensive workplace HIV programmes (Federal HIV and AIDS Prevention and Control Office 2007:8). These VHCT sites are for the general public but they are often not designed to address adolescents' special needs.

VHCT services are reported not to be tailored for adolescents (UNAIDS 2001:33). The report further states that there is very little information on VHCT services for young people (UNAIDS 2001:33). The same UNAIDS report states that, in many high-prevalence areas, young people, especially young women, are at high risk from HIV infection yet they often have no access to VHCT services. The report described young people's special vulnerabilities and a particular vulnerability of young women to HIV; however, this has not been translated into increasing access to VHCT services for them (UNAIDS 2001:33). This is one of the barriers to VHCT availability and accessibility for young people (Boswell \& Baggaley 2002:15).

The expenses of VHCT are also mentioned in this study, and are supported in literature as a barrier in terms of access by young persons. Boswell and Baggaley (2002:16) reported that for VHCT services to reach young people, VHCT must be free. Any attempt to introduce or scale up VHCT for young people must take cost analysis in to consideration (Boswell \& Baggaley 2002:16). Similarly, the finding strengthens the results obtained from a 2004 study done on knowledge of and attitude towards, voluntary counselling and testing for HIV in North West, Ethiopia in which $93.8 \%$ of respondents reported their willingness to use VHCT services if such services were to be made available free of charge (Shtaye $e t$ al. 2004:86). Short waiting periods for the VHCT services would also enhance utilisation of these services (Boswell \& Baggaley 2002:15). The current study also mentioned short waiting periods as necessary to enhance utilisation of VHCT services. A study carried out in 2005 in Ethiopia also reported long waiting periods as a deterrent to accessing VHCT services, and suggested a waiting period of thirty minutes as suitable (Federal Ministry of Health/HAPCO, AAU).

\section{Recommendations}

Several recommendations were made that would improve access to VHCT services by adolescents in Ethiopia. The recommendations are: 
- School adolescents should be provided with a VHCT service at their schools, with trained peer educators to increase access to the same service for the school age population.

- Adolescents and parental VHCT information sharing should be encouraged and strengthened, so that adolescents can learn from their parents without fear of cultural barriers that could lead to stigma, discrimination and other possible consequences.

- VHCT education should focus on avoiding stigmatising and discriminatory behaviour, so that students will develop positive attitudes towards people living with HIV and AIDS.

- VHCT services should be free in order to attract more utilisation by adolescents.

- Quality of counselling should be considered the most important factor for all counsellors, as this could motivate adolescents' VHCT service seeking.

\section{Conclusion}

In order to address the needs of adolescents, it is important to provide youth-friendly services and youth-friendly service provider sites. But, according to the Ethiopia VHCT guideline 2007, available VHCT services are found in integrated services, stand-alone counselling and testing services, outside health facilities, and outreach VHCT services, which are provided for special populations such as schools and government agencies (Federal HIV and AIDS Prevention and Control Office 2007:8). VHCT services currently available do not seem to address adolescents' needs because statistics show minimal usage by adolescents (Federal HIV and AIDS Prevention Control Office 2007:8).

The increase in the use of VHCT services, such as HIV counselling and testing by adolescents is encouraging for both policy makers and healthcare workers. In addition to providing quality VHCT services, the development of affordable and effective medical care for people living with HIV is essential to address the urgent need to improve access and quality of services (Joint Publications of IPPF South Asia Regional Office and UNFPA 2004:6).

\section{Acknowledgements}

The authors would like to acknowledge the University of South Africa for affording them the opportunity to do the study and publish the manuscript.

\section{Competing interests}

The authors declare that they have no financial or personal relationships which may have inappropriately influenced them in writing this paper.

\section{Authors' contributions}

A.A.G. (High Schools) was responsible for data collection, data analysis. G.T.T. (University of South Africa) was responsible for writing and critically reviewing and approving the manuscript.

\section{References}

Abiy, A., 2006, 'Perception of high school students towards voluntary HIV counselling and testing, using health belief model in Butajira', SNNPRMPH thesis, Department of Community Health, Addis Ababa University, 25.

Ajdukovic, M., 1998, 'Displaced adolescents in Croatia: sources of stress and posttraumatic stress reaction', Journal of the association of nurses in AIDS care 33(129), 209-217.

Alemu, S., Abseno, N., Degu, G., Wondmikun, Y. \& Amsalu, S., 2004, 'Knowledge and attitude towards voluntary counselling and testing for HIV: A community based study in northwest Ethiopia', Ethiopian Journal of Health Development 18(2), 82-89.

Amsale, C., 2002, 'Perceived sufficiency and usefulness of IEC materials and methods on HIV/AIDS among high school youth in Addis Ababa', MPH thesis, Department of Community Health, Addis Ababa University, 45-47.

Boswell, D. \& Baggaley, R.B., 2002, 'Voluntary counselling and testing (VCT) and youns people: a summary overview', Family Healthy International (FHI) 3, 15-16.

Burns, N. \& Grove, S.K., 2001, 'The practice of nursing research: conduct, critique \& utilization, 4th edn., W.B. Saunders, Philadelphia.

CDC 2005, HIV/AIDS Surveillance Report, 2004, Atlanta: US Department of Health and Human Services 16, CDC: 1-46, viewed 30 March 2012, from http://www.cdc. gov/hiv/topics/surveillance/resources/reports/2004report

Central Statistical Agency, 2006, Ethiopia demographic and health survey 2005, Addis Ababa, Ethiopia 221-254.

City Government of Addis Ababa Education Bureau Planning and Programming Service, 2011, Education statistics draft annual abstract 2003 EC, Education Management Information (EMIS), Unpublished, Addis Ababa, Ethiopia.

Drucker, P., 1993, Post-capitalist Society, Butterworth-Heinemann, Oxford.

Ethiopia Population Census commission 2008, Summary and statistical report of the 2007 population and housing census: population size by age and sex, Addis Ababa, Ethiopia, 8-19.

Federal Ministry of Health/HAPCO, AAU, CSA, EPHA, 2006, HIV/AIDS behavioural surveillance survey (BSS) Ethiopia 2005 round two, Federal Ministry of Health, Addis Ababa.

Fontaine, K.L. \& Fletcher, J.S., 2004, Essentials of mental health nursing, Addison Wesley, New York.

FMOH and Federal HAPCO., 2007, Guidelines for HIV counselling and testing in Ethiopia: 4,8.

Griesel-Roux, E., 2004, 'A case study exploring learner's experiences of HIV/AIDS programmes', Unpublished D.Phil psychology dissertation, University of Pretoria.

Hall, H.I., Ruiguang, S., Rhodes, P., Prejean J., Qian A., Lee, L.M., Karon, J., Brookmeyer, R., Kaplan, E.H., McKenna, M.T. \& Janssen, R.S., 2008, Estimation of HIV incidence in the United States. JAMA 300, 520-529. http://dx.doi.org/10.1001/ jama.300.5.520, PMid: 18677024, PMCid: 2919237

Hogg, M.A., \& Vaughan, G.M., 2005, Social Psychology, Pearson/Prentice Hall, New Jersey.

Joint Publications of IPPF South Asia Regional Office and UNFPA, 2004, Integrated HIV voluntary counselling and testing services in to reproductive health settings stepwise: guidelines for program planner, manager and service providers 1-7, 12-19, 27-30

Joubert, G. \& Ehrlich, R. (eds.), 2007, Epidemiology: a research manual for South Africa, 2nd edn., Oxford University Press, Cape Town.

Kabiru, C.W., Beguy, D., Chriton, J. \& Zulu, E.M., 2011, 'HIV/AIDS among youth in urban informal settlements in Kenya: What are the correlates of and motivations for HIV
testing?' BMC Public Health 11(1), 37- 49. http://dx.doi.org/10.1186/1471-2458testing?' BMC Public Health 11(1), 37-49. h
11-685, PMid: 21888666, PMCid: 3189135

Kartz, D., 1960, 'The functional approach to the study of attitudes', The Public Opinion Quarterly 24(2), 163-204. http://dx.doi.org/10.1086/266945

Lyons, M., 2005, 'The impact of HIV/AIDS on children families and communities: Risks and realities of childhood during the HIV epidemic', United Nations Development program, Issue paper N0.32.

Minister of Finance and Economic Development, 2010, 2010 MDGs report, trends and prospective for meeting MDGs by 2015. Ethiopia 31-34.

Mwandira, J.H.G., 2008, 'A comparative study of effectiveness of Youth Peer HCT Counsellors and adult counsellors in promoting uptake of HIV counselling and testing among the youth in Lilongwe District of Malawi', Unpublished dissertation. University of South Africa, Pretoria.

Parker, R. \& Aggleton, P., 2002, HIV/AIDS-related stigma and discrimination: A Conceptual Framework and an Agenda for Action, viewed 10 July 2012, from http://pdf.usaid.gov/pdf_doc/Pnacq832.pd

Pikard, J. L., 2009, 'HIV Voluntary Counselling and Testing among Kenyan Male Youth aged 13-15 years: The Theory of Planned behaviour Applied', A thesis submitted to the school of Kinesiology and health Studies in conformity with the requirements for the degree of masters of Science, Queens University, Canada.

Polit, D.F., Beck, C.T. \& Hungler, B.P., 2004, Essentials of nursing research: methods, appraisal and utilization, 4th edn., Lippincott, Philadelphia.

Polit, D.F. \& Beck, C.T., 2004, Nursing research: principles and methods, 7th edn., Lippincott Williams \& Wilkins, London.

Shangula, M.N., 2006, Factors affecting voluntary counselling and HIV testing among pregnant woman in Tsumeb District, Oshikoto Region, Namibia. Unpublished Thesis, Masters of Public Health degree, University of the Western Cape, South Africa. 
Shtaye, A., Nuru, A., Getu, D., Yared, W. \& Solomon, A., 2004, 'Knowledge and attitude towards voluntary counselling and testing for HIV: a community-based study in towards voluntary counselling and testing for HIV: a community-based study i
North West Ethiopia', Ethiopian Journal of Health Development 18(2), 83-87.

Tegegn, A., Yazachew, M. \& Gelaw, Y., 2008, 'Reproductive Health Knowledge and Attitude among adolescents: A community based study in Jimma Town, Southwest Ethiopia', Ethiopian Journal of Health Development 22(3), 143-151.

Thupayagale-Tshweneagae, G., 2010, 'Behaviors used by HIV-Positive adolescents to prevent stigmatization in Botswana', International Nursing Review 260-264. http://dx.doi.org/10.1111/j.1466-7657.2009.00792.x, PMid:20579163

Tuckman, B., 1978, Conducting Educational Research, Harcourt Brace Jovanovitch, San Diego. PMid:618623

Van Dalen, D.B., 1999, Understanding educational research, McGraw-Hill, New York. UNAIDS, 2001, The impact of voluntary counselling and testing: a global review of the benefits and challenges, Geneva, Switzerland 8-9, 32-35.
UNAIDS, 2008, Report on the global AIDS epidemic, Geneva, Switzerland.

UNAIDS, 2010, Global report: UNAIDS report on the global AIDS epidemics, Geneva, Switzerland.

UNAIDS/WHO, 2007, AIDS epidemic update, Geneva, Switzerland.

United Nations, 2010a, Population and HIV/AIDS wall chart, Department of Economic and Social Affairs, population division 1-2.

United Nations, 2010b, The millennium development goals report 41-46.

USAID/Family Health International, 2004, VCT TOOLKIT. HIV voluntary counselling and testing: a reference guide for counsellors and trainers 1-4, 45-49, USAID, Addis Ababa.

UNICEF, 2011, The state of the world's children 2011, Adolescence: An age of opportunity, viewed 20 July 2011, from http://www.unicef.org

WHO/UNAIDS, 2001, Technical consultation on VCT, Zimbabwe Harare 3-16. 